University of Nebraska - Lincoln

DigitalCommons@University of Nebraska - Lincoln

Publications from USDA-ARS / UNL Faculty

U.S. Department of Agriculture: Agricultural

Research Service, Lincoln, Nebraska

2014

Soil and Water Conservation: Our History and Future Challenges

Douglas Karlen

USDA-ARS, doug.karlen@ars.usda.gov

Gary A. Peterson

Colorado State University, gary.peterson@colostate.edu

Follow this and additional works at: https://digitalcommons.unl.edu/usdaarsfacpub

Karlen, Douglas and Peterson, Gary A., "Soil and Water Conservation: Our History and Future Challenges" (2014). Publications from USDA-ARS / UNL Faculty. 1637.

https://digitalcommons.unl.edu/usdaarsfacpub/1637

This Article is brought to you for free and open access by the U.S. Department of Agriculture: Agricultural Research Service, Lincoln, Nebraska at DigitalCommons@University of Nebraska - Lincoln. It has been accepted for inclusion in Publications from USDA-ARS / UNL Faculty by an authorized administrator of DigitalCommons@University of Nebraska - Lincoln. 


\section{Soil and Water Conservation: Our History and Future Challenges}

\section{Douglas L. Karlen* \\ USDA-ARS \\ National Lab. for Agriculture and the \\ Environment \\ 2110 University Blvd. \\ Ames, IA 50011-3120}

\section{Gary A. Peterson \\ Dwayne G. Westfall \\ Dep. of Agronomy \\ Colorado State Univ. \\ Ft. Collins, CO 80523}

Remembering our past is an essential first step into the future. Building on that philosophy, we summarize two presentations from a 2012 Soil Science Society of America (SSSA) symposium focused on soil management challenges in response to climate change to examine: (i) how the Soil and Water Management and Conservation Division evolved, (ii) how soil management research approaches have changed since the division was founded, and (iii) how division scientists are helping an increasing global population respond to a dynamic and changing climate. Our division roots and much of soil science in general were literally and figuratively grounded in field research. Here, we examine the transition from field-scale observational to reductionist research approaches, discuss why the latter approach is inadequate for addressing landscape-scale, cropping system response to climate change, and suggest an alternative soil management research approach for our future. The evolution, challenges, and success of a four-factor landscape-scale cropping system study in the U.S. Great Plains is used to illustrate the proposed approach. Recent developments in research programs that promote a more comprehensive systems approach are also provided. We conclude with optimism that by identifying new funding priorities and approaches, SSSA scientists and engineers will be able to help solve several complex and wicked 21 st century natural resource problems associated with a dynamic and changing climate and a population of more than nine billion people.

S oil was often described by the late W.E. Larson, our mentor, colleague, and friend, as "the thin layer covering the planet that stands between us and starvation." Many other authors, including those quoting Plato (Hillel, 1991) have stressed the importance of soil management and the dire consequences of failing to do so (e.g., Lowdermilk, 1953; Montgomery, 2007). The SSSA defines soil management as

"the sum total of all tillage and planting operations; cropping practices; fertilizer, lime, herbicide and insecticide applications; irrigation and other treatments conducted on or applied to a soil for the production of plants."

As soil scientists and long-time members of the SSSA Soil and Water Conservation and Management Division, our objectives are (i) to examine the development of our discipline by reviewing what division members have focused on since its formation, (ii) how research approaches have changed, and (iii) how research priorities and approaches need to change again to ensure that the thin mantle of soil can sustainably meet food, feed, fiber, and fuel requirements of more than nine billion people living with an ever-changing and dynamic climate. Our assumptions

Supplemental material available online.

Soil Sci. Soc. Am. J. 78:1493-1499

doi:10.2136/sssaj2014.03.0110

Received 20 Mar. 2014.

*Corresponding author (doug.karlen@ars.usda.gov).

(C) Soil Science Society of America, 5585 Guilford Rd., Madison WI 53711 USA

All rights reserved. No part of this periodical may be reproduced or transmitted in any form or by

any means, electronic or mechanical, including photocopying, recording, or any information storage and retrieval system, without permission in writing from the publisher. Permission for printing and for reprinting the material contained herein has been obtained by the publisher. 
are that (i) global weather patterns are dynamic and changing, (ii) global population and desired standards of living are increasing, (iii) interactions associated with a changing climate and increasing human resource demands creates multiple soil and water management challenges, and (iv) division members have the integrative knowledge, skills, and abilities needed to help provide sufficient food, feed, fiber, and fuel to sustainably meet these challenges.

Our intent is to: (i) challenge individuals interested in soil management to develop a broader perspective of their discipline, (ii) illustrate the importance of research approaches that address landscape-climate interactions, and (iii) present arguments for an increased emphasis on long-term experiments to solve present and future soil management problems associated with a changing climate.

\section{HISTORY OF SOIL \\ MANAGEMENT RESEARCH}

The literal and figurative roots of soil science lie in field research. Through observations such as those chronicled by Plato (Hillel, 1991) and many others in subsequent centuries, field studies (i.e., soil management practices) were conceived to solve problems limiting food, feed, and fiber supplies for local communities. As basic scientific knowledge increased, a new level of understanding of soil management was achieved via chemical analysis. The classic example of linking field research and the chemistry laboratory was the establishment of the Rothamsted Research Facility in Harpenden, UK, by Sir J.B. Lawes and J.M. Gilbert in 1843. At that time, agricultural field research was conducted by establishing a variety of treatments and imposing them across the landscape in large experimental units but with no replication. This research approach, grounded in observation, was the norm for soil management research until the early 20th century. Significant advances were made by Lawes and Gilbert via this crude technique. For example, they were the first to show that $\mathrm{NO}_{3}-\mathrm{N}$ leached out of soils in measurable amounts that were related to management treatments.

When scholars such as R.A. Fisher (1890-1962) developed the concept of "experimental error" and attaching probabilities to treatment differences, a revolution in field techniques was started. In his 2003 discourse regarding the advent of statistics, Sir Walter Bodmer from Hartford College in Oxford, UK, stated that

"the most notable [development] was the use of the word variance and the development of the analysis of variance, and the stimulus for the ideas for factorial experimentation."

This led quickly to the concepts of randomization, replication, and experimental design, and the revolution picked up steam. Factorial treatment arrangements allowed scientists to observe and quantify interactions among variables, which led to much more specificity in experiment design and analysis.
The formation and evolution of our SSSA division provides an excellent case study to chronicle changes in soil management research. Organized as one of the initial "sections" when the SSSA was founded on 18 Nov. 1936, our current division was known as the Soil Technology Section. The SSSA sections were renamed "divisions" and assigned specific Roman numerals (i.e., Division VI) in 1947, and in 1949, scientists and engineers affiliated with this group became known as Division VI-Soil Conservation, Irrigation, Drainage, and Tillage. Nine years later, Division VI was renamed the Soil and Water Management and Conservation Division, and in 1962, the "S" prefix was adopted and the Roman numerals were dropped to create Division S-6. At the end of 2012 the S-6 was dropped, thus giving the division its current name. The common link throughout the entire period is that agricultural scientists and engineers affiliated with the division have always been a highly productive, integrative, and problem-solving group. To illustrate the breadth of topics addressed by division members, the supplemental material lists abbreviated titles from division publications for 1936 through 2011. This information is summarized to show productivity on an annual basis in Fig. 1 and through a subjective classification of dominant research topics in Table 1.

The transition from a large-scale, non-replicated field observation approach to a statistically based, controlled experimental design had a profound impact on soil management research, primarily by introducing the concept of reductionism. This transition was embraced by many agricultural researchers because it was intended to remove or at least minimize the effects of variability on the experimental results and thus increase our ability to understand the nature of complex systems by making inferences based on interactions among their parts or by reducing the treatments to simpler, more controllable components, or perhaps more fundamental properties and processes.

So how did a reductionist approach focusing on individual components such as soil organic matter, compaction, crusting, erosion, aggregation, infiltration, or tillage (Table 1) affect traditional soil management research, its associated field studies,

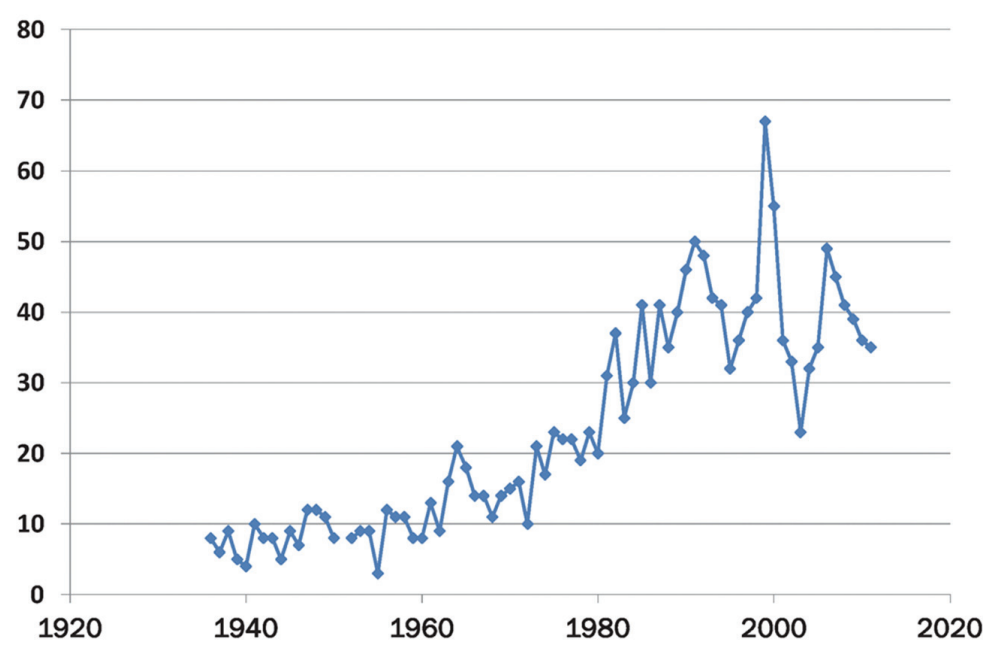

Fig. 1. Annual number of Soil and Water Conservation and Management Division publications between 1936 and 2011. 
and our ability to extrapolate to complex issues such as increasing climate variability? We suggest that the transition resulted in more narrowly focused studies, within well-defined but narrow inference spaces (Fig. 2), with fewer linkages among experiments and less emphasis on integrated agricultural system properties. Furthermore, because of the experimental emphasis on individual soil and water management components, there was ultimately a loss of, or at least a reduction in, the information gained about the soil and crop management system per se.

\section{NEW APPROACHES FOR SOIL MANAGEMENT RESEARCH}

Reductionist research has undoubtedly provided a wealth of information and an excellent understanding of many basic soil properties and processes that are affected by and influence many land management decisions. We suggest, however, that in isolation a reductionist approach does not provide answers to complex questions such as how increasingly fluctuating weather patterns, variable landscapes, and diverse cropping systems interact or what soil and crop management strategies need to be adjusted in response to those factors and others to provide the food, feed, fiber, and fuel needed to support more than nine billion people.
Table 1. A subjective characterization of soil and water management research components focused on by division scientists and engineers in their 1936 to 2011 publications.

\begin{tabular}{lc}
\multicolumn{1}{c}{ Research topic } & Contribution to total \\
\hline & $\%$ \\
Compaction and crusting & 7 \\
Aggregation & 7 \\
Runoff & 5 \\
Tillage & 16 \\
Soil organic matter or soil organic C & 10 \\
Nutrient management & 5 \\
Erosion and erodibility & 17 \\
Infiltration & 6 \\
Irrigation & 7 \\
Production and productivity & 6 \\
Mulch, residue, and cover crops & 9 \\
Other & 5 \\
\hline
\end{tabular}

The limitations introduced by attempting to remove or minimize variability when conducting and interpreting soil management field research have been recognized by many others and provide one reason why new approaches such as defining inference spaces using GIS technologies (Fig. 2) have been de-

\section{INFERENCE SPACE OF SELECTED NEBRASKA RESEARCH AND EXTENSION SITES}

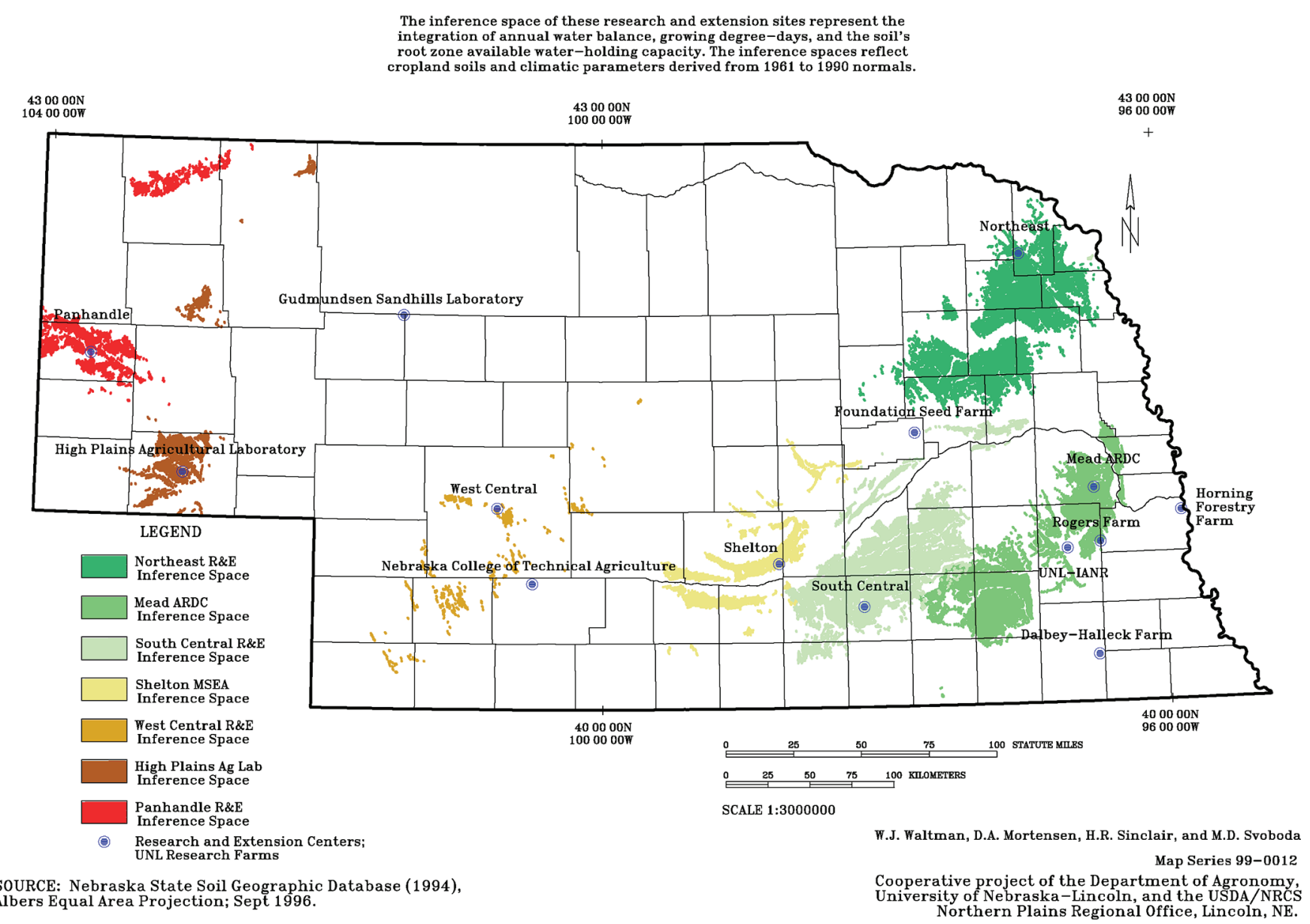

Fig. 2. The concept of well-defined but narrow inference spaces is illustrated by those areas for which field studies at Nebraska research stations would be considered representative. 
veloped (Waltman et al., 1999). Figure 2 illustrates the inference space associated with the various research and extension (R\&E) centers associated with the University of Nebraska-Lincoln. The inference domains reflect areas with $90 \%$ similarity in the three biophysical properties (growing degree days, annual water balance, and root zone water-holding capacity) at each R\&E site. The domains describe windows of driving forces that influence the selection of appropriate crop cultivar or hybrid, tillage system, and other agronomic practices.

Field research results are often strongly affected by climate and landscape properties (especially those properties that influence soil moisture content), and those properties vary across space and time. A probability surface that describes the occurrence of a field study's critical environmental factors can be used to incorporate temporal variance into a study's inference space model. These domains help identify areas of similarity in which research results would probably be applicable. Using new research approaches and visualization processes as illustrated in Fig. 2 enables users to define inference zones that they believe are most relevant to their research or production environment. These techniques can also be used to help guide future research, to extend research results to end users, and to help producers manage risk.

To illustrate how using only reductionist research approaches limited soil and water scientist and engineer abilities to address complex or "wicked" (Batie, 2010) problems, we will use the wheat (Triticum aestivum L.)-fallow management strategy to illustrate the complexity of weather, landscape, and cropping system interactions. This soil, water, and crop management system has dominated U.S. Great Plains agriculture for nearly a century, but is it a sustainable soil and crop management practice? The wheat-fallow system evolved as a management practice to achieve higher wheat yields by capturing and storing soil water during the fallow period and increasing available N. However, based on our experiences (e.g., Farahani et al., 1998a, 1998b; Halvorson et al., 2002; Lamb et al., 1985; McGee et al., 1997; Peterson et al., 1996; Peterson and Westfall, 2004; Power and Peterson, 1998; Unger et al., 2006), the system is neither sustainable nor capable of meeting the productivity demands of the 21 st century.

There are several reasons, primarily associated with the fallow period, for reaching these conclusions. They include: (i) inefficient water storage with only $25 \%$ of the precipitation being captured and retained during the fallow period; (ii) high soil erosion potential during the fallow period; (iii) increasing problems with grassy weeds such as jointed goat grass (Aegilops cylindrica Host) and downy brome (Bromus tectorum L.); (iv) rapid and increased loss of soil C; and (v) a generally low economic return per unit land area. The wheat-fallow cropping system expanded rapidly during and after the Dust Bowl to stabilize wheat crop yields from year to year. During the 1980s, however, we began to recognize that this soil and crop management system may not be an optimum strategy for the Great Plains physiographic region. Unfortunately, there was no available research data to offer producers alternatives for a system that was gradually being rec- ognized as flawed and extremely vulnerable to changing weather and climatic patterns. Although literally hundreds of experiments had been conducted in the Great Plains to determine how to improve wheat-fallow systems and even to replace them with more intensively cropped systems, those experiments could not be linked in a manner that would help solve the problem of sustainability. Simply stated, the dominance of component research had gradually resulted in: (i) no consistent or systematic treatment of cropping systems across locations, landscape positions, and/or years; (ii) virtually no multiyear climatic data associated with the soil management publications, (iii) no specific information describing the relationships between different soil resources and cropping systems, and (iv) no way to connect the pieces of information being obtained through numerous, well-designed, and statistically valid studies.

\section{LANDSCAPE AND CLIMATE INTERACTION RESEARCH}

An attempt was made, beginning in the mid-1980s, to address the sustainability problem of Great Plains dryland cropping systems. A four-factor study was initiated in Colorado to provide answers to questions consistently being raised by scientists and producers by creating an experiment that simultaneously addressed cropping system, landscape position, precipitation gradient, and time interactions (Peterson et al., 1993). The overarching research objective of the study was to identify sustainable dryland cropping systems that would: (i) maximize precipitation use efficiency, (ii) improve soil productivity, and (iii) increase economic return to farmers. To expand the inference space needed for the study to have value to Colorado farmers, the integrated, comprehensive field experiment was established at three Colorado locations in 1985 to provide a potential evapotranspiration gradient based on annual cropping season open-pan evaporation losses of 1600, 1725, and $1975 \mathrm{~mm}$. A soil gradient at each location was imposed by establishing the potential cropping system treatments in parallel strips extending from toeslope to summit positions at each location (Fig. 3). Two replicates of four different cropping systems were imposed at each site. They were: (i) wheat-fallow, (ii) wheat- corn (Zea mays L.)-millet [Pennisetum glaucum (L.) R. Br.]-fallow; (iii) continuous opportunity cropping, and (iv) perennial grass.

Abandonment of proven reductionist research approaches for this new, more intensive soil and crop management system for the U.S. Great Plains was met with skepticism by many research and extension colleagues. The critics' perspectives were that: (i) two replicates were not enough to detect treatment differences, (ii) the approach introduced too much variability (i.e., variance) and therefore the data would not be publishable, and (iii) it was going to be too difficult to manage the sites, and since the studies were going to have to be monitored for several years, there simply would not be sufficient research funds to continue the experiments. Finally, many believed it would be impossible to conduct such complex studies with the available equipment and personnel. 


\section{Colorado Experiment}
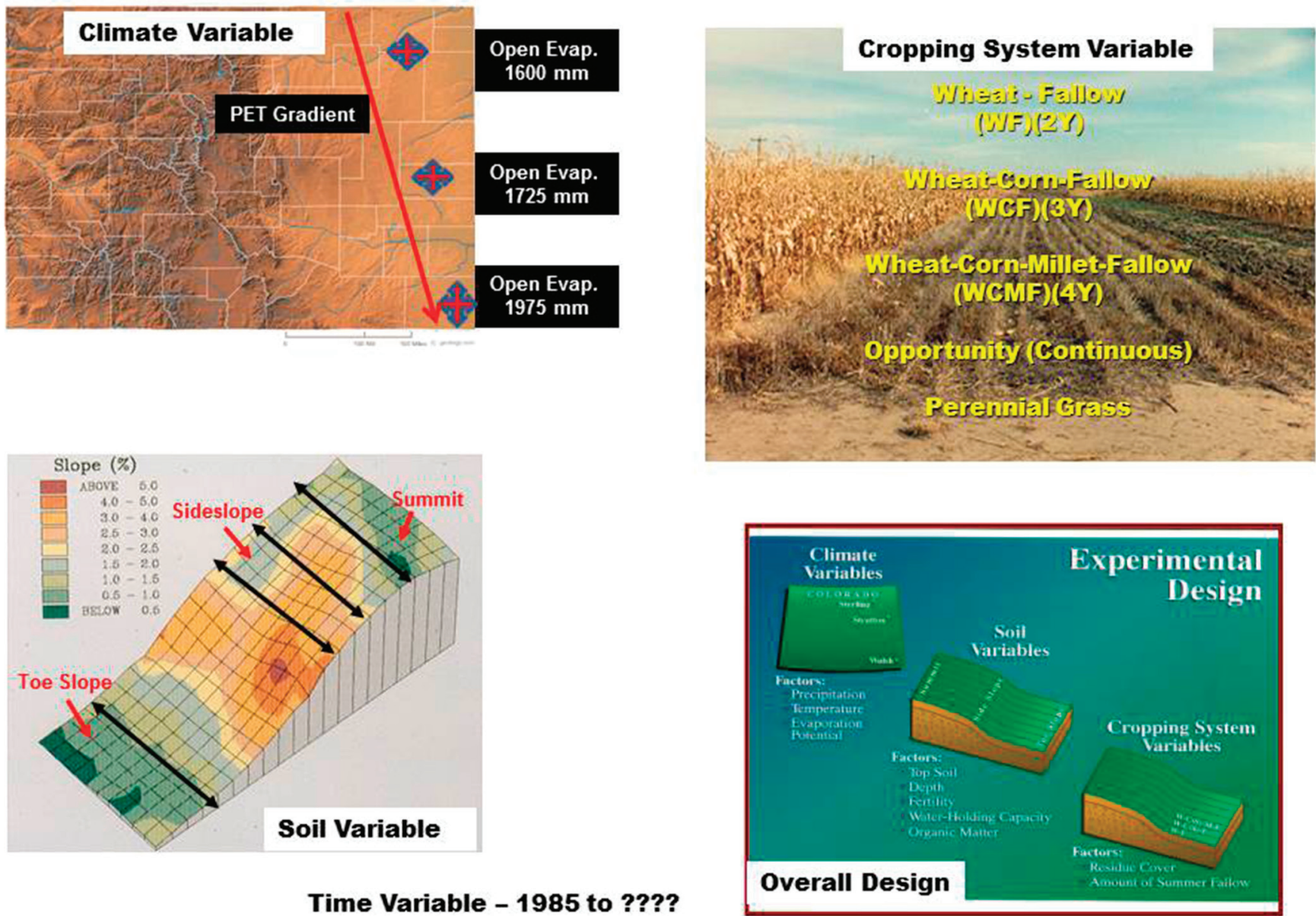

Time Variable - 1985 to ????

Fig. 3. Climate, soil, cropping systems, and experimental design of a long-term Colorado systems experiment.

Fortunately, during the same time period, several other research and extension teams were beginning to more aggressively attack soil and water management problems using a systems approach. In the U.S. Midwest, the Management Systems Evaluation Area (MSEA) studies (Anderson et al., 1993; Hatfield et al., 1993, 1999), on-farm comparisons of alternate management practices (Karlen et al., 1995), and Conservation Effects Assessment Project (CEAP) studies (Karlen, 2008) provide a few examples of how soil management research was changing. The difference between MSEA, CEAP, and other multi-location projects from what had become the predominant soil and water management research model was coordination among locations so that inference spaces associated with each individual study could be increased.

Returning to the Great Plains Cropping Systems study, what really happened during the past three decades and what has been learned by applying a systems research approach to soil and crop management problems? First, cropping intensification resulted in increased aboveground biomass production. The studies also showed that cropping system yields were lowest in the most stressed environments and highest in those that were least stressed. Cropping system intensification could increase grain production by $75 \%$, with the benefits being independent of climate and soil factors. Intensification also increased the soil organic C content, decreased the surface soil bulk density, improved soil aggregation, and improved effective porosity. Documenting those systems changes was not only important for providing Colorado farmers with improved recommendations to enhance economic and environmental sustainability of their operations, it also provided multiple coordinated field sites for scientists interested in using reductionist studies to focus on improving our scientific understanding of the mechanisms responsible for the changes that were being observed at the systems level. Furthermore, this Great Plains research study coincided with the development of soil quality-soil health concepts that emphasize the importance of assessing biological, chemical, and physical responses to soil management practices (Andrews et al., 2004; Karlen et al., 2001, 2003, 2006) and the resilience of those responses to stress factors such as changing climate or weather patterns. The Great Plains study also demonstrated to the soil and water management research community the importance and value of carrying out long-term, coordinated field studies (Peterson et al., 2012). 


\section{LONG-TERM, LANDSCAPE-SCALE RESEARCH CHALLENGES}

To meet the 21 st century challenge of providing adequate food, feed, fiber, and fuel for more than nine billion people living with increased climate variability, we agree with others (e.g., Bertsch and Pierzynski, 2013) that sustainable intensification is the key for enhanced soil security and productivity. So what is the limiting factor to landscape-scale soil management research? Again, we argue that it is the reluctance by both researchers and those funding the projects to move from the reductionist model, through which small pieces of information can continue to be developed with short-term, i.e., 3- to 5-yr grant funding, to more integrated, long-term studies that require a substantial investment in both infrastructure and its maintenance. Landscapescale, systems research requires a long-term, trans-disciplinary approach with adequate funding to develop and sustain a multilocation field research infrastructure for multiple decades. We are not advocating that landscape-scale research replace all component research because those studies are crucial for providing a mechanistic understanding of the processes being affected by the system. Rather, we are simply stating that both component and landscape-scale systems research approaches should be used in a complementary manner to address complex problems such as those associated with an increasingly variable climate.

Examples of how both research approaches can be effectively combined to address complex soil and crop management problems created by increasing climate variability include the established Long-Term Ecological Research (LTER) model (LTER Network Office, 2012) and the recently introduced USDA-ARS Long-Term Agroecological Research (LTAR) program. The goals for this new program (LTAR-SRS Writing Team, personal communication, 2013) are to ensure sustained crop and livestock production and ecosystem services from agroecosystems and to forecast and verify the effects of environmental trends, public policies, and emerging technologies. Through a shared research strategy (SRS) the LTAR Network is being designed to capitalize on the strengths of 18 initial sites by creating common geographically and temporally scalable research studies and databases to deliver knowledge and applications addressing: (i) agroecosystem productivity; (ii) climate variability and change; (iii) conservation and environmental quality; and (iv) socioeconomic viability and opportunities. By combining long-term, intensive and extensive, field-scale and watershed-scale research approaches, the overarching goal is to reduce the uncertainties associated with scaling experimental data gathered through multiple studies for regional production and/or policy assessments. The LTAR research approach will also facilitate evaluation of tradeoffs between intensified commodity production practices needed to supply food, feed, and fiber resources for nine billion people and sustainable delivery of non-commodity agroecosystem services.

Another strategy for providing the infrastructure for landscape-scale soil management systems research would be for the USDA-National Institute for Food and Agriculture (NIFA) to create a new category of research aimed specifically at landscape studies. For both LTAR- and NIFA-initiated programs, we suggest that new research projects would compete for funds, but once awarded there should be a reasonable guarantee that a minimum level of funding would continue to be provided for at least a decade or more, provided the sites were continuing to produce high-quality, science-based information that was truly meeting stakeholder and general public needs.

The LTAR has been initiated, with 10 sites receiving funding through the fiscal year (FY) 2014 ARS allocation, and eight additional sites are scheduled to be funded in FY 2016. We also recognize that initiating a NIFA program such as this may require redefining how land grant universities use traditional Hatch Act funding - a concept that is consistent with viewpoints recently expressed by Bertsch and Pierzynski (2013). Such change will not be easy or popular, but undoubtedly, meeting the food, feed, fiber, and fuel needs of nine billion people by the middle of this century will require not only new research and technology transfer strategies but also innovative and creative ways to fund both intensive and extensive soil management research.

Another important contribution of LTER, LTAR, our proposed NIFA landscape studies, and other multi-location research programs (e.g., the ARS Greenhouse gas Reduction through Agricultural Carbon Enhancement network [GRACEnet] and Resilient Economic Agricultural Practices [REAP] team) is the development and maintenance of comprehensive, multilocation databases. One example is the GRACEnet/REAP database that was recently opened for public access (Del Grosso et al., 2013). Multi-location research results contributed to these databases through coordinated, landscape-scale systems projects can then be used as input for simulation models, which provide an effective way to assimilate extensive amounts of component research results. Currently, we are not aware of any simulation models dedicated to soil management, although the Landscape Environmental Assessment Framework (LEAF) that was developed (https://www.youtube.com/watch?v=mEsL6zgk60Q) to help identify sustainable biomass feedstock harvest strategies has excellent potential for doing so. The LEAF model is structured to seamlessly link various crop yield, wind and water erosion, nutrient cycling, soil C, and economic models to provide soil management guidelines that can be used to address complex problems such as increasingly variable weather patterns. Another way to use multi-location soil management data would be to model the soil structure in response to various management practices using an approach such as the least-limiting water range, which was recently used to project sustainable bioenergy feedstock production (Benjamin and Karlen, 2014).

\section{SUMMARY AND CONCLUSIONS}

As shown in both Table 1 and the supplemental material, reductionist research has provided a tremendous amount of soil management information and an improved understanding of many soil properties and processes. In isolation, however, that research approach is not sufficient to meet complex landscapescale challenges under increasingly variable climatic conditions. 
Therefore, we conclude that landscape-scale soil management field research is vital for soil security and to meet increasing global demands for food, feed, fiber, and fuel. A new research paradigm with a long-term horizon is crucial and must be aggressively pursued. Therefore, as one of our favorite comedians would say, now is the time to simply "git 'er done!"

\section{ACKNOWLEDGMENTS}

We want to thank Ms. Becky Roland for her exceptional effort to compile the information on division publications presented in the supplemental material.

\section{REFERENCES}

Anderson, J.L., R.H. Dowdy, J.A. Lamb, G.N. Delin, R. Knighton, D. Clay, and B. Lowery. 1993. Northern Cornbelt Plains Management System Evaluation Area. In: Proceedings of the Agricultural Research to Protect Water Quality Conference, Minneapolis, MN. 21-24 Feb. 1993. Soil and Water Conserv. Soc., Ankeny, IA. p. 39-47.

Andrews, S.S., D.L. Karlen, and C.A. Cambardella. 2004. The Soil Management Assessment Framework: A quantitative soil quality evaluation method. Soil Sci. Soc. Am. J. 68:1945-1962. doi:10.2136/sssaj2004.1945

Batie, S.S. 2010. Taking conservation seriously as a wicked problem. In: P. Nowak and M. Schnepf, editors, Managing agricultural landscapes for environmental quality: II. Achieving more effective conservation. Soil and Water Conserv. Soc., Ankeny, IA. p. 143-155.

Benjamin, J.G., and D.L. Karlen. 2014. LLWR techniques for quantifying potential soil compaction consequences of crop residue removal. BioEnergy Res. 7:468-480. doi:10.1007/s12155-013-9400-x

Bertsch, P., and G. Pierzynski. 2013. Reshaping land grant institutions to solve the global grand challenges of the 21st century. CSA News 58:28. doi:10.2134/csa2013-58-9-17

Del Grosso, S.J., J.W. White, G. Wilson, B. Vandenberg, D.L. Karlen, R.F. Follett, et al. 2013. Introducing the GRACEnet/REAP data contribution, discovery, and retrieval system. J. Environ. Qual. 42:1274-1280. doi:10.2134/jeq2013.03.0097

Farahani, H.J., G.A. Peterson, and D.G. Westfall. 1998a. Dryland cropping intensification: A fundamental solution to efficient use of precipitation. Adv. Agron. 64:197-223. doi:10.1016/S0065-2113(08)60505-2

Farahani, H.J., G.A. Peterson, D.G. Westfall, and L.R. Ahuja. 1998 b. Soil water storage in dryland cropping systems: The significance of cropping intensification. Soil Sci. Soc. Am. J. 62:984-991. doi: $10.2136 /$ sssaj $1998.03615995006200040020 x$

Halvorson, A.D., G.A. Peterson, and C.A. Reule. 2002. Tillage system and crop rotation effects on dryland crop yields and soil carbon in the central Great Plains. Agron. J. 94:1429-1436. doi:10.2134/agronj2002.1429

Hatfield, J.L., J.L. Anderson, E.E. Alberts, T. Prato, D.G. Watts, A. Ward, et al. 1993. Management systems evaluation areas: An overview. In: Proceedings of the Agricultural Research to Protect Water Quality Conference, Minneapolis, MN. 21-24 Feb. 1993. Soil and Water Conserv. Soc., Ankeny, IA. p. 1-15.
Hatfield, J.L., D.B. Jaynes, M.R. Burkart, C.A. Cambardella, T.B. Moorman, J.H. Prueger, and M.A. Smith. 1999. Water quality in Walnut Creek watershed: Setting and farming practices. J. Environ. Qual. 28:11-24. doi: $10.2134 /$ jeq1999.00472425002800010002x

Hillel, D. 1991. Out of the earth: Civilization and the life of the soil. Univ. of California Press, Berkeley.

Karlen, D.L. 2008. A new paradigm for natural resources research: The conservation effects assessment project. J. Soil Water Conserv. 63:220A. doi:10.2489/jswc.63.6.220A

Karlen,D.L.,S.S.Andrews, andJ.W.Doran.2001.Soilquality: Currentconceptsand applications. Adv. Agron. 74:1-40. doi:10.1016/S0065-2113(01)74029-1

Karlen, D.L., S.S. Andrews, B.J. Wienhold, and J.W. Doran. 2003. Soil quality: Humankind's foundation for survival—A research editorial by conservation professionals. J. Soil Water Conserv. 58:171-179.

Karlen, D.L., M.D. Duffy, and T.S. Colvin. 1995. Nutrient, labor, energy, and economic evaluations of two farming systems in Iowa. J. Prod. Agric. 8:540-546. doi:10.2134/jpa1995.0540

Karlen, D.L., E.G. Hurley, S.S. Andrews, C.A. Cambardella, D.W. Meek, M.D. Duffy, and A.P. Mallarino. 2006. Crop rotation effects on soil quality at three northern Corn/Soybean Belt locations. Agron. J. 98:484-495. doi:10.2134/agronj2005.0098

Lamb, J.A., G.A. Peterson, and C.R. Fenster. 1985. Wheat fallow tillage system's effect on a newly cultivated grassland soils' nitrogen budget. Soil Sci. Soc. Am. J. 49:352-356. doi:10.2136/sssaj1985.03615995004900020016x

Lowdermilk, W.C. 1953. Conquest of the land through 7000 years. Agric. Inf. Bull. 99. USDA Soil Conserv. Serv., Washington, DC.

LTER Network Office. 2012. Long-term ecological research 2012 annual report. Dep. of Biology, Univ. of New Mexico, Albuquerque.

McGee, E.A., G.A. Peterson, and D.G. Westfall. 1997. Water storage efficiency in no-till dryland cropping systems. J. Soil Water Conserv. 52:131-136.

Montgomery, D.R. 2007. Dirt: The erosion of civilizations. Univ. of California Press, Berkeley.

Peterson, G.A., A.J. Schiegel, D.L. Tanaka, and O.R. Jones. 1996. Precipitation use efficiency as affected by cropping and tillage systems. J. Prod. Agric. 9:180-186. doi:10.2134/jpa1996.0180

Peterson, G.A., D.J. Lyon, and C.R. Fenster. 2012. Valuing long-term field experiments: Quantifying the scientific contribution of a long-term tillage experiment. Soil Sci. Soc. Am. J.76:757-765. doi:10.2136/sssaj2011.0413

Peterson, G.A., and D.G. Westfall. 2004. Managing precipitation use in sustainable agroecosystems. Ann. Appl. Biol. 144:127-138. doi:10.1111/j.1744-7348.2004.tb00326.x

Peterson, G.A., D.G. Westfall, and C.V. Cole. 1993. Agroecosystem approach to soil and crop management research. Soil Sci. Soc. Am. J. 57:1354-1360. doi:10.2136/sssaj1993.03615995005700050032x

Power, J.F., and G.A. Peterson. 1998. Nitrogen transformations, utilization, and conservation as affected by fallow tillage method. Soil Tillage Res. 49:3747. doi:10.1016/S0167-1987(98)00153-6

Unger, P.W., W.A. Payne, and G.A. Peterson. 2006. Water conservation and efficient use. In: G.A. Peterson et al., editors, Dryland agriculture. 2nd ed. Agron. Monogr. 23. ASA, CSSA, and SSSA, Madison, WI. p. 39-85.

Waltman, W.J., D.A. Mortensen, H.R. Sinclair, and M.D. Svoboda. 1999. Inference space of selected Nebraska research and extension sites. Map Ser. 99-0012. Dep. of Agronomy, Inst. of Agric. and Nat. Resour., Univ. of Nebraska, Lincoln. 